\title{
Peningkatan pengetahuan aneka olahan cabai merah besar untuk kemandirian ekonomi masyarakat
}

\author{
Increased Knowledge of Various Processed Big Red Chili \\ for Community Economic Independence
}

\author{
Deny Utomo ${ }^{1)}$, Kholid Murtadlo ${ }^{2)}$, Syaiful $^{3)}$, Cahyuni Novia ${ }^{4)}$ \\ ${ }^{1}$ Fakultas Pertanian, Universitas Yudharta Pasuruan \\ email : denyut369@gmail.com \\ ${ }^{2}$ Fakultas Ilmu Sosial Pemerintahan, Universitas Yudharta Pasuruan \\ email : ahmadkholid@gmail.com \\ ${ }^{3}$ Fakultas Teknik, Universitas Nurul Jadid Probolinggo \\ email : syaiful@gmail.com \\ ${ }^{4}$ Fakultas Teknik, Universitas Nurul Jadid Probolinggo \\ email : vhie771108@gmail.com \\ Informasi Artikel: \\ Dikirim: 10/09/2019; ditinjau: 15/09/2019; disetujui: 30/09/2019
}

\begin{abstract}
Large red chili is one of the mainstay agricultural commodities in Karanganyar Village. Production of 85 tons of large red chili can be obtained by farmers, if there is abundant production. Every time the harvest of large red chili is not always perfect, there is often an imperfect shape of chili. Farmers usually call a large red chili reject, with a percentage of 10\% (8.5 tons) each time. The price of this large red chili is cheaper than the large red chili that looks perfect. The goal to be achieved in community service activities is to increase the income of the PKK group of women through the processing of various processed large red chilies into powder, shredded rice and sauce. The method is done by using lecture and demonstration methods accompanied by training materials, and delivered directly by conducting demonstration relating to the process of making powder, shredded and sauce starting from the handling of raw materials, how to use production equipment, the process of mixing materials, cooking to packaging. The overall results of partners can make a variety of processed large red chillies and can do the packaging well.
\end{abstract}

Keywords: big red chili, shredded, sauce, powder

\begin{abstract}
ABSTRAK
Komoditas cabai merah besar merupakan salah satu komoditas andalan pertanian di desa tersebut. Produksi 85 ton cabai merah besar bisa didapatkan petani, apabila terjadi produksi melimpah. Setiap kali masa panen cabai merah besar yang dihasilkan tidak selalu sempurna, sering kali terdapat bentuk cabai yang tidak sempurna. Para petani biasa menyebut cabai merah besar afkir, dengan jumlah prosentase $10 \%(8,5$ ton $)$ setiap kali panen. Harga cabai merah besar afkir ini dijual lebih murah dari cabai merah besar yang bentuknya sempurna. Tujuan yang ingin dicapai dalam kegiatan pengabdian kepada masyarakat ini adalah meningkatkan pendapatan masyarakat kelompok ibu-ibu PKK melalui pengolahan aneka olahan cabai merah besar menjadi bubuk, abon dan saus. Metode yang dilakukan dengan menggunakan metode ceramah dan demonstrasi disertai materi pelatihan, serta disampaikan langsung dengan melakukan pendemontrasian yang berkenaan dengan proses pembuatan bubuk, abon dan saus mulai
\end{abstract}


dari penanganan bahan baku, cara penggunaan alat-alat produksi, proses pencampuran bahan, pemasakan sampai pengemasan. Hasil secara keseluruhan mitra kerja dapat membuat aneka olahan cabai merah besar serta dapat melakukan pengemasan dengan baik.

Kata kunci : cabai merah besar, abon, saus, bubuk

\section{PENDAHULUAN}

Cabai merupakan komoditas potensial yang memiliki nilai ekonomi tinggi dan berpotensi untuk terus dikembangkan (Supriadi et al., 2018). Beberapa alasan penting dalam pengembangan komoditas cabai, antara lain merupakan komoditas unggulan bernilai ekonomi tinggi, banyak digunakan untuk konsumsi rumah tangga (80\%) maupun keperluan industri pengolahan makanan sebesar 20\% (Dirjen Hortikultura, 2015). Cabai memiliki aktivitas antioksidan, kandungan fenol dan capsaicinoid yang tinggi. Terdapat dua jenis tanaman cabai yang umumnya dibudidayakan di Indonesia yaitu, cabai merah besar (Capsicum annuum L.) dan cabai rawit (Capsicum frutescens L.) (Loizzo et al., 2015). Menurut FAOSTAT (2015), Indonesia menduduki peringkat ke empat sebagai negara dengan produksi cabai tertinggi di dunia setelah China, Mexico dan Turki sedangkan angka produktivitasnya masih lebih rendah dibandingkan negara China yang mencapai 21.89 ton ha-1.

Cabai merah (Capsicum annuum L.) merupakan salah satu sayuran yang permintaannya cukup tinggi, baik untuk pasar domestik maupun ekspor ke mancanegara dan sebagian besar penduduk Indonesia mengonsumsi cabai dalam bentuk segar, kering atau olahan biasanya dalam bentuk olahan saus sambal (Taufik, 2016). Cabai segar mempunyai daya simpan yang sangat singkat, sering terjadi kerusakan secara mekanis dan fisik. Oleh karena itu diperlukan penanganan pasca panen yang maksimal mulai dari pemanenan sampai pengangkutan. Jika tidak, akan membuat cabai segera menjadi rusak, membusuk, dan mengalami tingkat penyusutan yang lebih tinggi. Nilai kerusakan yang terjadi mulai dari pemanenan sampai ke tingkat pengecer dapat berkisar 23\% (David, 2018).

Pengeringan bukan hanya metode yang diadopsi secara tradisional dalam melestarikan makanan dan sayuran yang mudah rusak tetapi juga mengurangi volume penyimpanan serta meningkatkan umur simpan (Reis et al., 2013). Metode pengeringan yang berbeda diadopsi untuk mengoptimalkan kompromi antara efisiensi dan kualitas, seperti pengeringan matahari, pengeringan udara panas (Fudholi et al., 2013; Mihindukulasuriya et al., 2015), pengeringan microwave (Saengrayap et al., 2015) dan pengeringan beku (Topuz et al., 2011). Pengeringan matahari adalah metode yang diadopsi secara tradisional untuk pengeringan cabai dengan durasi waktu 7-20 hari (tergantung pada cuaca) yang bertujuan mengurangi kadar air hingga tingkat yang diinginkan 10-15\% (Janjai et al., 2011).

Cabai merah merupakan bahan makanan penting yang digunakan sebagai makanan dan sebagai bumbu karena warna khas mereka, kepedasan, rasa dan aroma yang berbeda (Bogusz Jr et al., 2018). Studi epidemiologi menunjukkan manfaat dari makanan pedas dalam mengurangi angka kematian dan meningkatkan kualitas kesehatan (Bley et al., 2012; Ly et al., 2015). Ada banyak manfaat nutraceutical yang terkait dengan konsumsi cabai, seperti antiinflamasi (Chen dan Kang, 2013), analgesik (Evangelista, 2015), regulasi glukosa darah (Yang et al., 2014) dan antioksidan (Shahidi dan Ambigaipalan, 2015; Sora et al., 2015; Sarafi et al., 2018). Sifat fungsional sering dikaitkan dengan Capsicum peppers, sebagian besar karena makanan ini menjadi sumber karotenoid (Kim et al., 2016), vitamin $\mathrm{C}$, vitamin $\mathrm{E}$, alkaloid, flavonoid, dan capsaicinoids (Hallmann dan Rembiałkowska, 2012) . 
Cabai merah besar kering (Capsicum annuum var. Annuum) adalah salah satu bumbu alam yang paling banyak digunakan dalam industri makanan karena warna, rasa dan kepedasannya (Maurya et al., 2018). Produk cabai merah besar kering sekarang secara teratur digunakan dalam beberapa masakan seperti pizza, campuran makanan, salad dan sup instan. Beberapa parameter seperti warna, panas, asam askorbat, fenolik dan kandungan capsaicin telah dipelajari untuk mengevaluasi kualitas cabai kering (Deepa et al., 2013; Tilahun et al., 2013). Berbagai bentuk produk olahan berbahan baku cabai merah antara lain; abon cabai, bubuk cabai, cabai merah giling, dan lainnya. Produk abon cabai merah dan cabai merah giling, umumnya dipasarkan melalui sistem door to door, pesanan dan memasarkan produknya melalui kios-kios terdekat (Elizabeth, 2018).

Permasalahan utama masyarakat di Desa Karanganyar adalah belum mengenal teknologi pengolahan cabai merah besar. Sebagian besar cabai merah besar di Desa Karanganyar hanya dijual dalam bentuk segar. Hal ini terjadi karena ketidakpahaman masyarakat setempat tentang jenis produk lain yang dapat dihasilkan dari bahan baku cabai merah besar, masyarakat juga belum memahami teknologi sederhana apa yang dapat diaplikasikan pada cabai merah besar yang mereka jual. Mereka beranggapan bahwa cabai merah besar hanya bisa jual dalam bentuk segar (belum diolah). Padahal hanya dengan sentuhan teknologi yang sederhana cabai merah besar dapat menjadi produk olahan yang bernilai tinggi dibandingkan dengan menjual dalam bentuk belum diolah. Salah satunya adalah mengolah cabai merah besar menjadi saus, abon dan cabai bubuk.

Permasalahan lainnya adalah peningkatan produksi bahan baku cabai merah besar pada saat panen raya sebesar 85 ton dengan harga jual Rp. 4000,-/kg, sehingga harga tersebut lebih murah lagi dan sangat jauh dari harga normal. Kondisi tersebut memaksa para petani cabai untuk tetap menjual cabai dalam bentuk segar, karena terdesak oleh kebutuhan, bahkan ditemukan juga banyak cabai merah yang terbuang secara sia-sia.

Pengolahan cabai merah besar menjadi aneka olahan produk nantinya akan dilakukan oleh mitra sasaran yaitu, kelompok ibu-ibu PKK RT. 010/RW.004 Desa Karanganyar. Pelatihan pengolahan tersebut nantinya akan terjalin silaturahmi yang semakin kuat, sehingga secara otomatis akan berdampak pada ketentraman kehidupan bermasyarakat yang lebih baik.

\section{METODE PELAKSANAAN}

\section{Bahan}

Bahan aneka olahan cabai merah besar untuk bubuk meliputi; cabai merah besar. Bahan baku pembuatan abon, yaitu; cabai merah besar, cabai merah besar, cabai kecil, bawang putih, ebi kering, daun jeruk, kaldu bubuk, garam halus, dan gula halus. Sedangkan bahan baku pembuatan saus meliputi; cabai merah besar, cabai rawit kecil, air, gula pasir, garam, bubuk kaldu, maizena, tomat, bawang putih, dan jeruk nipis.

\section{Alat}

Alat yang digunakan adalah blender, grinder, oven, sealer, dandang, kompor, pisau, talenan, sutil, bak penampungan bahan, wajan, sendok pengaduk, nampan cetakan, sepet, dan plastik kemasan.

\section{Metode / Pelaksanaan penelitian}

Metode pengumpulan data dilakukan dengan melakukan wawancara pada pengurus PKK dan masyarakat. Pengumpulan data ini dimaksudkan untuk mengetahui status sosial, pendidikan dan motivasi mitra kerja dalam kegiatan PKM yang dilaksanakan agar target luaran dapat tercapai.

Target luaran dilakukan penilaian pada saat pelaksanaan kegiatan praktek pembuatan bubuk, abon, dan saus dari cabai merah besar dan pemantauan keberlanjutan kegiatan dengan memanfaatkan media sosial sebagai sarana promosi produk. 


\section{HASIL DAN PEMBAHASAN}

Hasil pelaksanaan kegiatan Program Kemitraan Masyarakat melibatkan dua mitra. Mitra kerja yang ikut dalam kegiatan pelatihan pembuatan produksi dan pengemasan adalah 35 orang dengan distribusi pendidikan 5 orang Sarjana, 8 orang SMU, 10 orang SMP dan 12 orang SD. Secara umum, pendidikan mitra kerja cukup baik dan data yang ditemui menunjukkan bahwa tidak ada seorang pun dari peserta yang pernah mengetahui cara pembuatan bubuk, abon, dan saus dari cabai merah besar.

Rendahnya pengetahuan diversifikasi cabai merah besar mitra kerja dengan berlimpahnya bahan baku cabai merah besar di desa Karanganyar merupakan fenomena yang menarik perhatian tim kerja untuk melatih dan mentransfer pengetahuan pembuatan bubuk, abon, dan saus dari cabai merah besar. Tabel 1 memperlihatkan jumlah mitra kerja yang pernah membuat bubuk, abon, dan saus dari cabai merah besar sebelum kegiatan PKM dilaksanakan

Tabel 1. Mitra kerja yang pernah membuat bubuk, abon, dan saus dari cabai merah besar sebelum PKM

\begin{tabular}{lccc}
\hline & Bubuk & Abon & Saus \\
\hline Pernah & 0 & 0 & 0 \\
Belum pernah & 35 & 35 & 35 \\
Jumlah & 35 & 35 & 35 \\
\hline
\end{tabular}

Tabel 2. Produk yang dihasilkan menarik, dapat dikembangkan dan bernilai jual

\begin{tabular}{lccc}
\hline & Bubuk & Abon & Saus \\
\hline Ya & 35 & 35 & 30 \\
Tidak & 0 & 0 & 5 \\
Jumlah & 35 & 35 & 35 \\
\hline
\end{tabular}

Tabel 3. Bahan baku mudah diperoleh dan cara pembuatan produk mudah

\begin{tabular}{lccc}
\hline & Bubuk & Abon & Saus \\
\hline Ya & 35 & 35 & 35 \\
Tidak & 0 & 0 & 0 \\
Jumlah & 35 & 35 & 35 \\
\hline
\end{tabular}

Mitra kerja yang berjumlah 35 orang belum pernah membuat bubuk, abon, dan saus dari cabai merah besar (Tabel 1). Setelah melaksanakan kegiatan, ternyata $100 \%$ mitra kerja dapat membuat produk olahan cabai merah besar dengan baik yaitu secara fisik dan rasa bubuk, abon, dan saus menarik, sehingga dapat dikembangkan sebagai produk olahan dari cabai merah besar (Tabel 2). Kondisi produk akan lebih menarik dan ketahanan produk meningkat dengan dilakukan pengolahan dan pengemasan yang benar.

Peralatan pengemasan yang dimiliki mitra kerja menjadi modal penting dalam pengembangan produk dan peningkatan nilai jual bubuk, abon, dan saus dari cabai merah besar. Dasar dalam pengembangan produk yaitu dengan bahan dasar cabai merah besar sangat mudah didapatkan di desa Karanganyar. Produk bubuk, abon, dan saus dari cabai merah besar juga relatif mudah di buat oleh mitra kerja pada saat pelatihan produksi (Tabel 3).

\section{KESIMPULAN}

Kesimpulan dari kegiatan PKM yang telah dilakukan dapat disimpulkan bahwa:

1. Seluruh mitra kerja dapat membuat aneka olahan cabai merah besar serta melakukan pengemasan dengan baik.

2. Produk aneka olahan cabai merah besar yang dihasilkan pada pelatihan produksi menarik dan dapat dikembangkan.

3. Bahan dasar pembuatan produk aneka olahan cabai merah besar yang mudah didapatkan di Desa Karanganyar.

\section{UCAPAN TERIMA KASIH}

Penulis mengucapkan terima kasih kepada seluruh pihak yang telah membantu dalam pelaksanaan kegiatan PKM dan seluruh pihak yang telah membantu dalam penelitian ini terutama kepada DPRM Dikti, Universitas Yudharta Pasuruan, Universitas Nurul Jadid Probolinggo, dan Kelompok Ibu-ibu PKK RT.010/RW.004 Karanganyar Kabupaten Probolinggo. 


\section{DAFTAR PUSTAKA}

Bley, K., Boorman, G., Mohammad, B., McKenzie, D., \& Babbar, S. (2012). A comprehensive review of the carcinogenic and anticarcinogenic potential of capsaicin. Toxicologic pathology, 40(6), 847-873.

Bogusz Jr, S., Libardi, S. H., Dias, F. F., Coutinho, J. P., Bochi, V. C., Rodrigues, D., ... \& Godoy, H. T. (2018). Brazilian Capsicum peppers: capsaicinoid content and antioxidant activity. Journal of the Science of Food and Agriculture, 98(1), 217-224.

Chen, L., \& Kang, Y. H. (2013). Antiinflammatory and antioxidant activities of red pepper (Capsicum annuum L.) stalk extracts: comparison of pericarp and placenta extracts. Journal of Functional Foods, 5(4), 1724-1731.

David, J. (2018). Technology to lengthen of storage of chili. Jurnal Pertanian Agros, 20(1), 22-28.

Deepa, G. T., Chetti, M. B., Khetagoudar, M. C., \& Adavirao, G. M. (2013). Influence of vacuum packaging on seed quality and mineral contents in chilli (Capsicum annuum L.). Journal of food science and technology, 50(1), 153-158.

Dirjen Hortikultura. (2015). Statistik produksi komoditas sayur. http://www.hortikultura.pertanian. go.id. [Diakses tanggal 21 Agustus 2018].

Elizabeth, R. (2018). Akselerasi agroindustri dan nilai tambah: faktor pendukung pencapaian dayasaing produk dan percepatan pembangunan pertanian di Indonesia. UNES Journal of Agricultural Scienties, 2(1), 1-18.

Evangelista, S. (2015). Novel therapeutics in the field of capsaicin and pain. .Expert Rev Clin Pharmacol, 8, 373-355.

FAOSTAT. (2015). Countries by commodity: Top Production Chillies and Peppers, Green 2010-2012. http://faostat3.fao.org. [Diakses tanggal 19 Agustus 2018].
Fudholi, A., Othman, M. Y., Ruslan, M. H., \& Sopian, K. (2013). Drying of malaysian Capsicum annuum L. (red chili) dried by open and solar drying. International Journal of Photoenergy.

Hallmann, E., \& Rembiałkowska, E. (2012). Characterisation of antioxidant compounds in sweet bell pepper (Capsicum annuum L.) under organic and conventional growing systems. Journal of the Science of Food and Agriculture, 92(12), 2409-2415.

Janjai, S., Intawee, P., Kaewkiew, J., Sritus, C., \& Khamvongsa, V. (2011). A large-scale solar greenhouse dryer using polycarbonate cover: Modeling and testing in a tropical environment of Lao People's Democratic Republic. Renewable Energy, 36(3), 1053-1062.

Kim, J. S., An, C. G., Park, J. S., Lim, Y. P., \& Kim, S. (2016). Carotenoid profiling from 27 types of paprika (Capsicum annuum L.) with different colors, shapes, and cultivation methods. Food chemistry, 201, 64-71.

Loizzo, M. R., Pugliese, A., Bonesi, M., Menichini, F., \& Tundis, R. (2015). Evaluation of chemical profile and antioxidant activity of twenty cultivars from Capsicum annuum, Capsicum baccatum, Capsicum chacoense and Capsicum chinense: a comparison between fresh and processed peppers. LWT-Food Science and Technology, 64(2), 623-631.

Lv, J., Qi, L., Yu, C., Yang, L., Guo, Y., Chen, Y., ... \& Tang, Z. (2015). Consumption of spicy foods and total and cause specific mortality: population based cohort study. Bmj, 351, 3942-3949.

Maurya, V. K., Gothandam, K. M., Ranjan, V., Shakya, A., \& Pareek, S. (2018). Effect of drying methods (microwave vacuum, freeze, hot air and sun drying) on physical, chemical and nutritional attributes of five pepper (Capsicum annuum var. annuum) cultivars. Journal of the Science of Food and Agriculture, 98(9), 3492-3500. 
Mihindukulasuriya, S. D., \& Jayasuriya, H. P. (2015). Drying of chilli in a combined infrared and hot air rotary dryer. Journal of food science and technology, 52(8), 4895-4904.

Reis, R. C., Castro, V. C., Devilla, I. A., Oliveira, C. A., Barbosa, L. S., \& Rodovalho, R. (2013). Effect of drying temperature on the nutritional and antioxidant qualities of cumari peppers from Pará (Capsicum chinense Jacqui). Brazilian Journal of Chemical Engineering, 30(2), 337-343.

Saengrayap, R., Tansakul, A., \& Mittal, G. S. (2015). Effect of far-infrared radiation assisted microwave-vacuum drying on drying characteristics and quality of red chilli. Journal of food science and technology, 52(5), 26102621.

Sarafi, E., Siomos, A., Tsouvaltzis, P., Chatzissavvidis, C., \& therios, I. (2018). Boron and maturity effects on biochemical parameters and antioxidant activity of pepper (Capsicum annuum L.) cultivars. Turkish Journal of Agriculture and Forestry, 42.

Shahidi, F., \& Ambigaipalan, P. (2015). Phenolics and polyphenolics in foods, beverages and spices: Antioxidant activity and health effects-A review. Journal of functional foods, 18, 820897.

Sora, G. T. S., Haminiuk, C. W. I., da Silva, M. V., Zielinski, A. A. F., Gonçalves, G. A., Bracht, A., \& Peralta, R. M. (2015). A comparative study of the capsaicinoid and phenolic contents and in vitro antioxidant activities of the peppers of the genus Capsicum: an application of chemometrics. Journal of food science and technology, 52(12), 8086-8094.

Supriadi, D. R., Susila, A. D., \& Sulistyono, E. (2018). Penetapan Kebutuhan air tanaman cabai merah (Capsicum annuum L.) dan cabai rawit (Capsicum frutescens L.). Jurnal Hortikultura Indonesia, 9(1), 38-46

Taufik, M. (2016). Analisis pendapatan usaha tani dan penanganan pascapanen cabai merah. Jurnal Penelitian dan Pengembangan Pertanian, 30(2), 6672.

Tilahun, S., Paramaguru, P., \& Rajamani, K. (2013). Capsaicin and ascorbic acid variability in chilli and paprika cultivars as revealed by HPLC analysis. Journal of plant breeding and genetics, 1(2), 85-89.

Topuz, A., Dincer, C., Özdemir, K. S., Feng, H., \& Kushad, M. (2011). Influence of different drying methods on carotenoids and capsaicinoids of paprika (Cv., Jalapeno). Food chemistry, 129(3), 860-865.

Yang, H. J., Kwon, D. Y., Kim, M. J., Kim, D. S., Kang, S., Shin, B. K., ... \& Park, S. (2014). Red peppers with different pungencies and bioactive compounds differentially modulate energy and glucose metabolism in ovariectomized rats fed high fat diets. Journal of Functional Foods, 7, 246-256. 